\title{
CITY CENTRE REGENERATION BY REMOVING MOTORWAYS: IMPACTS ON MOBILITY AND URBAN LIFE
}

\author{
ELISABETH REDZA \& PHILIPPE BOUILLARD \\ Université Libre de Bruxelles, BATir dept. (Civ., Arch. and Urb. Eng.), Belgium
}

\begin{abstract}
The paper will focus on analysing urban motorway removal in a central urban context to improve mobility and enhance public life by means of upgraded public spaces. The objectives are to understand why removing or decreasing car infrastructure in city centres is essential for sustainable cities and what impact such refurbishments have on mobility and public life. The proposed methodology allows us to assess the quality of urban renewals by suppressing urban motorways in order to deliver a tool for designing successful public spaces and improving mobility in city centres. The comprehensive framework includes twenty-five sub-criteria defining the quality of renewals reflecting the government policy, the mobility experience, the identity of the neighbourhood and the urban space through attractiveness and liveliness on site, user's comfort and perception of safety. The multi-criteria framework is tested on three European case studies of (i) urban motorway removal (Paris), (ii) increase of soft mobility infrastructure (Lyon) and (iii) recovering of urban space (Madrid), though only the first one will be presented in the paper. Finally, it is important to note that the aim is not to demonise car use, but rather to restore a human scale in city centres.
\end{abstract}

Keywords: urban motorway removal, human scale, public space, soft mobility.

\section{INTRODUCTION}

A city is per definition a large scale human settlement. The connecting lines between these settlements are various types of streets, having their own characteristics and articulations tracing back to history. The largest public space in a city and often, the most forgotten, is the street. If public means accessible to the community, why are most of the centre street nowadays still primarily dedicated to cars?

The car problematic is one of the key points to be tackled by urban planning in the following decades in western countries, but also in developing. As the number of people grows day by day, it is important to think of a way to move easily without losing the freedom offered by the car.

The negative effects due to car use in an urban context are numerous: high energy consumption mostly from non-renewable sources, time losses due to congestion, impacts on health due to noise and air pollution, a sedentary lifestyle, accidents and the large amount of space dedicated to moving or still cars [1].

Is it important to acknowledge the fact that the mobility issue is complicated as it depends on a wide range of factors? In this study, however, the aim will lie on demonstrating the importance of the reduction of vehicle infrastructure to improve mobility by relying on soft transport modes and implementing concepts such as induced demand [2] and traffic evaporation [3] to significantly decrease the demand for vehicle use. As European city centres developed at walkable distances and nowadays still remain central poles with numerous touristic attractions, city centres have a high potential to return to a human scale by reducing the car infrastructure. The freed space is plead to be transformed into space for all users. Circulation and qualitative urban space are the main focus points of the transformed urban space. 


\section{RESEARCH METHODOLOGY}

The research methodology is based on the creation of a qualification system of a comprehensive framework to provide guidelines for refurbished spaces in the context of urban motorway removal. The proposed methodology is a multi-criteria analysis offering a comprehensive framework. The criteria are based on the checklist method created by Wojnarowska [4] in a study on town centre evaluation methods and Gehl's [5] tools for good design, developed in Cities for People. The tool is intended for practitioners of the construction sector as the ability to read spatial development is required. However, the subjective character and the time-dependency of events have to be taken into account during the analysis.

\subsection{Criteria}

The three main criteria relevant in such projects are the government policy, urban space and mobility experience. Thus, these three criteria will be given similar share on the comprehensive framework. A fourth criterion will be dedicated to the identity of the neighbourhood.

By assessing the goals of the policies and how these goals were translated into measures, it is possible to evaluate the sustainability of the traffic solutions. The focus lies on shifting to soft mobility and raising the awareness of the citizens. The refurbishments that do not fulfil these crucial aspects will be penalised as the government policy account for $30 \%$ of the total mark.

The improvement of urban space and mobility experience account together for the largest share $(75 \%)$. Both concentrate only on the refurbishment. The mobility includes the comfort and safety of the soft traffic modes, such as pedestrian and bike traffic, but public transport and access for people of different physical ability are also taken into account. The quality of the urban space depends on numerous parameters and thus accounts for $35 \%$. The category was separated into three sub-criteria being the attractiveness and liveability of the site, the offered user's comfort and the perception of safety. As the safety is strongly linked to the attractiveness and comfort of the project, the contribution of the parameter on the score of urban space is lower.

The last parameter is the identity of the neighbourhood. As designers don't have much impact on the surroundings and the main goal is to assess the refurbishments, the image of the neighbourhood was implemented into a category with a smaller share $(5 \%)$.

Urban space, mobility and the image of the neighbourhood are connected to the policy, as the government is the motor to change. However, the three categories are undeniably interconnected, but the proportion of the interconnection depends on the goals of the refurbishments, e.g. refurbishments focused on mobility will be less impacted by an average neighbourhood image than refurbishments focused on the creation of lively urban space.

Each parameter will be rated on a fulfilment degree from 0 to 5 , where 0 represents a complete lack of fulfilment and 5 an excellent fulfilment. The contribution of each parameter to the category score is equal. However, the contribution of the parameters to the total score depends on the proportion of the total mark that is given to the category. The categories are detailed below. It should be noted that the weighting factors are a first attempt to classify each parameter by its importance and can be modified to reflect the approach (axed on mobility/public space or both) or based on public participation. 
Table 1: Evaluation system.

\begin{tabular}{|c|c|c|c|c|c|}
\hline 0 & 1 & 2 & 3 & 4 & 5 \\
\hline $\begin{array}{l}\text { Complete } \\
\text { lack of } \\
\text { fulfilment } \\
(0 \%)\end{array}$ & $\begin{array}{l}\text { Very small } \\
\text { degree of } \\
\text { fulfilment } \\
(1-20 \%)\end{array}$ & $\begin{array}{c}\text { Small } \\
\text { degree of } \\
\text { fulfilment } \\
(21-40 \%)\end{array}$ & $\begin{array}{l}\text { Moderate } \\
\text { degree of } \\
\text { fulfilment } \\
(41-60 \%)\end{array}$ & $\begin{array}{c}\text { Good } \\
\text { degree of } \\
\text { fulfilment } \\
(61-80 \%)\end{array}$ & $\begin{array}{l}\text { Excellent } \\
\text { degree of } \\
\text { fulfilment } \\
(81-100 \%)\end{array}$ \\
\hline
\end{tabular}

Table 2: Criteria and sub-criteria of the comprehensive framework.

\begin{tabular}{|c|c|}
\hline \multicolumn{2}{|c|}{ Government policy (30\%) } \\
\hline GPOL1: & $\begin{array}{l}\text { Sustainable transport by calm traffic solutions or urban motorway removal for a } \\
\text { durable development of cities. Integration of soft mobility and use of intelligent } \\
\text { systems e.g. vehicle detecting traffic lights to allow continuous flows and avoid } \\
\text { unnecessary waiting times. }\end{array}$ \\
\hline GPOL2: & $\begin{array}{l}\text { Raising awareness around sustainable transport modes and the importance of urban } \\
\text { space through campaigns and implementing -legal- measures to reduce vehicle traffic } \\
\text { in order to incite to a modal shift. }\end{array}$ \\
\hline GPOL3: & $\begin{array}{l}\text { Informing the citizens and integrating their opinion in the design and construction } \\
\text { processes in order to achieve better results and satisfaction of both camps. The } \\
\text { communication includes meetings, signage, surveys... before and after the } \\
\text { implementation of the project to assess the improvements in users' satisfaction. }\end{array}$ \\
\hline \multicolumn{2}{|c|}{ The mobility experience (30\%) } \\
\hline MOBI1: & $\begin{array}{l}\text { Experience at street level pleasant through e.g. curvature of the street, facades with } \\
\text { abundant details or alternative routes to keep adventure surprising in order to attract } \\
\text { new potential users and allow a stimulating experience for long term users. }\end{array}$ \\
\hline MOBI2: & $\begin{array}{l}\text { Pedestrian movement having priority over car traffic. No physical or perceptive } \\
\text { barriers for pedestrians. The barriers are elements that impede on the pedestrian's } \\
\text { comfort, such as too narrow sidewalks, signage, trash bins positioned in a way that } \\
\text { people cannot pass by safely and unrestricted. The crossings are simple, safe and on } \\
\text { the street level. The paths avoid interruptions and long waiting times. }\end{array}$ \\
\hline MOBI3: & $\begin{array}{l}\text { Bicycle routes safe and easy to use which are protected from car traffic and/or } \\
\text { pedestrian fluxes, depending on goal of refurbishment. Protection from car traffic can } \\
\text { be achieved with a barrier, e.g. parked cars or greenery strip and is important to assure } \\
\text { the safety of the cyclists. To avoid physical fatigue and time losses due to restarting, } \\
\text { the bike routes propose a continuous journey with no or few interruptions. Materials } \\
\text { and textures adapted to cycling and width of bike path adapted to fluxes - larger paths } \\
\text { allow a large number of users. }\end{array}$ \\
\hline MOBI4: & $\begin{array}{l}\text { Good accessibility by full range of public transport, railway or waterway with stops } \\
\text { near important destinations and accessible from different regions. A good } \\
\text { accessibility involves short journeys, numerous and frequent public transport lines } \\
\text { and reliability. Eventual improvement of public transport, e.g. segregated lanes to } \\
\text { allow continuousness and avoid accidents or implementing express bus lines. Offering } \\
\text { an integrated infrastructure, e.g. bikes allowed on trains, public transport cohesive and } \\
\text { in tune with other soft modes. }\end{array}$ \\
\hline MOBI5: & $\begin{array}{l}\text { Equal and integrated access for people of different physical ability extending over the } \\
\text { whole site. }\end{array}$ \\
\hline
\end{tabular}


Table 2: Continued.

\begin{tabular}{|c|c|}
\hline \multicolumn{2}{|c|}{ Urban space (35\%) } \\
\hline \multicolumn{2}{|c|}{ Attractiveness and liveliness on site (15\%) } \\
\hline LIFE1: & $\begin{array}{l}\text { Diversity of planned programme, attractive for inhabitants and visitors: recreational, } \\
\text { leisure, trade, services and cultural activities proposed on the site for mixing social and } \\
\text { age categories and creating a lively public space. }\end{array}$ \\
\hline LIFE2: & $\begin{array}{l}\text { Diversity of unintended programme on area's without fixed spatial development, } \\
\text { enabling the organisation of temporary events or an unplanned use of space by e.g. } \\
\text { street artists in order to boost freedom of choice, activity, liveliness and attractiveness. } \\
\text { The appropriation of the project is reflected through the liveliness on site. }\end{array}$ \\
\hline LIFE3: & $\begin{array}{l}\text { Legibility of the space, by clear definition of use and equilibrated proportion of usable } \\
\text { versus non-usable space, in accordance with the scale of the project. Non-usable space } \\
\text { enhances the quality of the project. Public and private character explicitly defined. The } \\
\text { space has to be clearly defined in order for people to understand where they are } \\
\text { welcome or not. The space can be segregated with materials, fences, colours, signage. } \\
\text { The semi-private character of outdoor café terraces illustrates perfectly this parameter } \\
\text { as the space is actually a public space but people are unwanted if they are not } \\
\text { consuming. However, it is important that the difference is marked in an aesthetical and } \\
\text { respectful way, e.g. high, spiky fences do not reflect a positive image. }\end{array}$ \\
\hline LIFE4: & $\begin{array}{l}\text { Use of greenery, water or other systems improving the urban ecology to enhance the } \\
\text { attractiveness of the space and raise awareness amongst the citizens. }\end{array}$ \\
\hline LIFE5: & Aesthetic, clean and well-cared for development. \\
\hline \multicolumn{2}{|c|}{ User's comfort and staying opportunities (15\%) } \\
\hline STAY1: & $\begin{array}{l}\text { Protection and shelter against unfavourable climatic conditions: wind, rain, snow, cold } \\
\text { and heat in the form of awnings, sunshades, canopies, trees and wind screens. } \\
\text { Protection against unfavourable climatic conditions enables the use of outdoor space in } \\
\text { all weather conditions. This is the case for e.g. café terraces providing plaids, electrical } \\
\text { heating and wind screens during the winter and sun shading during the summer. }\end{array}$ \\
\hline STAY2: & $\begin{array}{l}\text { Noise pollution low enough to allow conversations and enhance the comfort of the } \\
\text { users. }\end{array}$ \\
\hline STAY3: & $\begin{array}{l}\text { Positive sensory experiences on street level: wealth of lines (primarily vertical), } \\
\text { textures, colours, relief, reflection and materials. Small-scale, open and active units. As } \\
\text { mostly found in historical commercial streets, an abundance of materials, colours, } \\
\text { details on small, open units offer a varied experience on the street level. On the } \\
\text { contrary, large, blind facades with few relief and primarily horizontal lines offer a } \\
\text { boring and unattractive experience. }\end{array}$ \\
\hline STAY4: & $\begin{array}{l}\text { Several types of urban furniture offering opportunities to stay or sit. Chairs, stairs, piles, } \\
\text { benches providing back protection. Infrastructure for activities. Urban furniture } \\
\text { structures the space and enhances the comfort of the users. In this context, urban } \\
\text { furniture is defined as all elements providing staying or sitting opportunities such as } \\
\text { benches, chairs, stairs, piles and frontage of buildings. Regarding the comfort, these } \\
\text { elements preferably provide back protection and pleasant textures and materials. The } \\
\text { arrangement of the seats is in proper relation to the activities in the area, directed to } \\
\text { interesting views (townscape, pedestrian flows, sun). Furniture composition allowing } \\
\text { intimacy of conversations. Not only is the design of the furniture important, but the } \\
\text { arrangement also plays a key role. Moveable furniture is e.g. very appreciated as one } \\
\text { can redirect or reposition the elements as liked, in order to create some distance between } \\
\text { people, move towards the edges of the space or create a talkscape - a smaller and } \\
\text { frequently dissociated composition allowing intimacy of conversations. Fixed furniture } \\
\text { should provide the same arrangement. }\end{array}$ \\
\hline STAY5: & $\begin{array}{l}\text { Elements providing cleanliness, responding to fundamental human needs and practical } \\
\text { aspects, such as trash bins, benches, drinking fountains, public toilets, bicycle racks, } \\
\text { bicycle rent points at convenient places and at appropriate intervals. }\end{array}$ \\
\hline
\end{tabular}


Table 2: Continued.

\begin{tabular}{|l|l|}
\hline Perception of safety on the public space (5\%) \\
\hline SAFE1: & $\begin{array}{l}\text { Adequate lighting of streets and pedestrian routes, frontages of buildings, plazas, } \\
\text { people and their activities at night. The perception of safety improves if the } \\
\text { surroundings is well-lit, e.g. light in boutiques. Light can also become an attraction on } \\
\text { itself. The design should also improve the perception of safety by allowing a clear } \\
\text { vision with e.g. low vegetation and avoiding dark corners. }\end{array}$ \\
\hline SAFE2: & $\begin{array}{l}\text { Natural surveillance by passers-by and inhabitants of adjacent apartment blocks, having } \\
\text { a view into the street and thus being able to call emergency services. Buildings on small } \\
\text { scale to allow the connection to the happing in the street. }\end{array}$ \\
\hline SAFE3: & $\begin{array}{l}\text { Overlapping activities throughout day and night creating a lively public realm during } \\
\text { varying hours due to programme. Lively public spaces create a feeling of safety as } \\
\text { people have direct visual contact on events and can eventually intervene. Eventual } \\
\text { presence of installations to be used during the night time, such as interactive light } \\
\text { installations. }\end{array}$ \\
\hline SAFE4: & $\begin{array}{l}\text { Presence of facilities and services providing monitoring and protection. However, the } \\
\text { presence of protection services has to be discrete to avoid being oppressive. The design } \\
\text { of the project allows a clear visibility and avoids dark corners. }\end{array}$ \\
\hline Identity of neighbourhood (5\%) \\
\hline IDEN1: & $\begin{array}{l}\text { Legibility of space by a clear definition of areas and intended use in neighbourhood. } \\
\text { Public and private character explicitly defined. }\end{array}$ \\
\hline IDEN2: & $\begin{array}{l}\text { Emphasising local identity by preservation of historic form of development and } \\
\text { highlighting urban and natural landscape. Revitalisation and reuse of heritage. }\end{array}$ \\
\hline IDEN3: & $\begin{array}{l}\text { Attractiveness of neighbourhood: diversity of programme, interest poles and } \\
\text { landmarks. Clean and well-cared for facades in neighbourhood. }\end{array}$ \\
\hline
\end{tabular}

\section{CASE STUDY: SEINE BANKS IN PARIS, FRANCE}

The Parc Rives de Seine project is located on the banks of the Seine River flowing through central Paris. The urban motorways were transformed into a pedestrian and soft mobility promenade in the heart of the French capital. By completely evicting the car from the riverfront, the banks have become a lively public space. The promenade is a new urban space in the centre of Paris, stretching over 7 kilometres. The specificity is the reversible character of the project, as the site has to be accessible for emergency services due to its location in a zone with high flood risks [6]. The objectives of the project are to give back the banks to allow a wider number of users - especially children - by offering a breathing and walking zone, to develop and diversify the economic and touristic activities linked to the river, to valorise the site as it has a unique significance for the city and to strengthen to ecological continuity in the area of the Seine [7].

\subsection{Analysis of urban space}

The analysis and collection of data has been performed based on literature and on-site extensive visit by the first author in April 2017.

\subsubsection{Linearity and rhythm}

The street is enclosed by the Seine River on one side and the elevated street level with residences on the other site. As it is situated below the street level with residences, the protection from car traffic is continuous because vehicle traffic is elevated. The area is thus surrounded and protected in its full linearity. As minimal interventions have been 


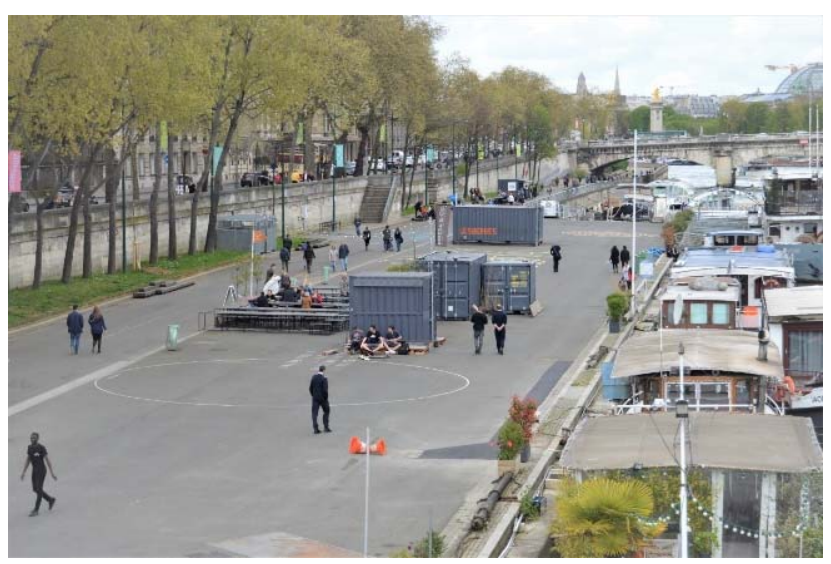

Figure 1: Containers used to shape the space. (Source: E. Redza.)

implemented, the space is still dictated by the conventional segregation of modes. The former road is now a space dedicated to soft mobility and vehicle use is prohibited. It forms a shared space for soft traffic, consisting of continuous flows of bicycles, roller-skaters, runners or walkers. The border zones, e.g. the sidewalk, have changed from moving to stationary activities, as sitting or staying opportunities are now provided.

The linear articulation and asphalt texture of the street is appreciated for activities including rolling. As thus cyclists, roller-skaters and people using steps follow the continuous, slightly curved shape of the former street, whereas skateboarders are to be found on section of the street transformed into large, open spaces. The site is a long promenade, where people use its length for activities requiring continuity, e.g. physical activities.

Even though the movement of people is mostly rectilinear, staying hubs are created around interest poles. The poles delimit smaller districts, which can be the sitting zone around a coffee shops, benches with a view on sports facilities, people watching a performance of street artists or the boundaries of a children's playground. The small cores reflect the human scale on a project that is very long-seemingly never-ending. The hubs offer a diversified experience during the journey as the use of the districts is depending on the proposed facilities or the way people use the space. The programme - intended or not - creates a rhythm in the promenade and equilibrates the perception of endless length.

\subsubsection{Reversible equipment}

In order to be accessible for emergency services, all modification to the street have to be temporary and sufficient space for a car to pass through should be available at any time. The installations on the project are reversible and the urban furniture is low-tech. Containers, moveable chairs and tables and wooden boards are found all over the promenade.

Lumber of wood serve as benches, creating intimate hubs, offering back protection and or redirect the view. Paintings on the ground indicate the path, suggest an activity, create a perimeter or just bring more colour. Freight containers are used as flexible shelter for coffee houses and other small catering. The containers are also used for auxiliary functions such as trade, services or artistic facilities like mini-ateliers. Moveable chairs and tables, sometimes containing board games, are placed around container cafés. A typical Parisian terrace arrangement, looking at passers-by, is proposed at most sitting hubs, but the placement of seating always enables the user to choose what he/she will look at. The elevated sidewalk 


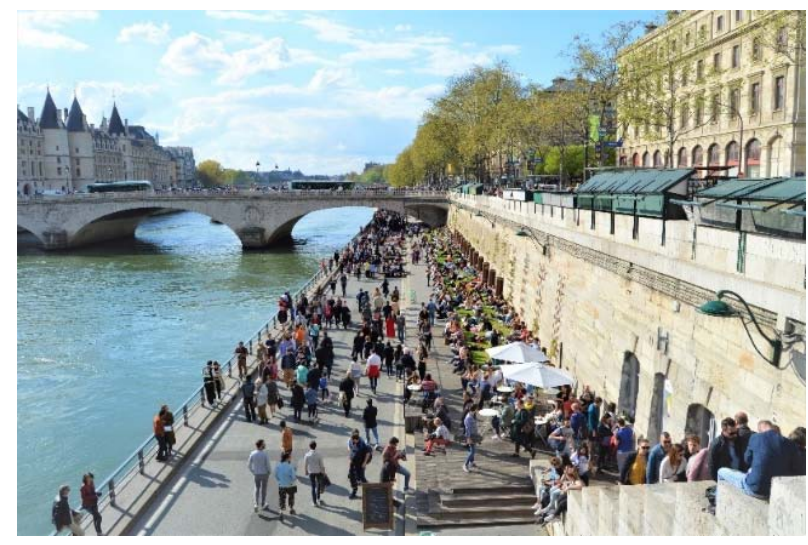

Figure 2: Linearity of the promenade. (Source: E. Redza.)

and the outline protection barrier to the river are used to stand or sit on. Climbing plants or children's playground ornament some sections of the high walls separating the bank from the street, without impeding on the historical value of the walls.

A floating garden enhances the green image of the promenade. In the surroundings of the floating garden, greenery is installed in unfixed boxes. The arrangement of the metal boxes creates small seating hubs providing intimacy of conversations with a view on the Seine. Smaller moveable greenery pots are put around cafés and on the barges, which improves the green image of the project.

The existing greenery with large trees on the sideways of the street was maintained. The few lawns around the trees on the left bank are not used, while the lawns on the right bank are used in a more dynamic way. People relax, sun-bathe or picnic on the grass. The overall picture of the banks is relatively green, but some sections lack (usable) greenery.

The provided activities cover all age categories, from children's play area to adult sports facilities. All social classes are welcome: pick-nicking is as much promoted as sitting around a coffee house.

As the site is located at the riverfront, accessible barges provide a diversified programme. Floating cafés, theatres and night clubs provide activities after dark and propose touristic activities on the Seine. The residential function of the boats also improves the perception of safety, as inhabitants on the street level do not necessarily have a direct view on the banks due to the lower position.

The temporary installations do not allow a change in materials. Thus, the biggest part of the site is asphalted. This is appreciated for gliding activities, but the comfort of pedestrians is limited. However, some sections on the right bank provide softer ground textures suited for physical activities. The feeling of segregation is still perceptible as the narrow sidewalks are not used if no activity is proposed.

\subsubsection{Shared space for soft mobility}

Due to the fact that the street remained unchanged, a modal segregation is still perceptible. The street became a shared space where soft mobility modes meet pedestrians, whereas the sidewalks are dedicated stop zones. On larger sections, the delimitation is less clear. Installations such as containers are for example placed in the middle of the space. However, a fair amount of space always permits linear traffic. 
The soft modes are not only used as a way of transportation, but leisure practices are abundant. The asphalted section formerly used by cars is nowadays mainly used by soft mobility alternatives, such as bikes, roller-skates, steps, and skateboards. The linearity of the promenade is appreciated for physical activities: soft traffic modes used for recreation mix up with numerous runners and walkers.

The extensive use of the space by soft mobility creates barriers in the way that people have to beware, but the shared space is working well even when crowded. People pay attention to what is happening around and adapt or limit their speed. As protection from car traffic is offered, the space is safe to use for all age categories. The presence of children testifies to the safety perception, even if protection on the waterfront is not always provided.

Bike renting station, coupled to bicycle racks - which are less used - are numerous and located at adequate intervals. Other services linked to soft mobility such as bike repairing are provided in freight containers. The former car tunnels, also unchanged, are mainly used for faster bicycle movements.

\subsubsection{Comfortable promenade}

The space has a good legibility - the semi-private character of cafés is clear, while the rest of the space is free to use. Sometimes the space is claimed by a group of people delimiting the needed space for their activity, e.g. skaters. The lack of directional signage is regrettable, since numerous cultural cores are located around the site. Being located in such a unique spot, it is important to redirect the view on landmarks by arranging the stopping opportunities in a way that offers interesting viewing axes. This is accomplished with various sitting facilities, but the abundance of events in the surroundings focusses the user's attention on the direct environment.

The installations are clean, aesthetical and well-cared for. Equipment providing more comfort to the users, such as dustbins, bicycle renting and parking, benches and tables are available at reasonable intervals. However, insufficient drinking fountains and a lack of seating when crowded were observed. More sitting opportunities can be easily provided with moveable chairs. The aesthetics could be improved with smaller reversible interventions e.g. greenery boxes or colourful containers, but the overall image is very pleasing. Shelter from unfavourable weather conditions is only provided through trees or under bridges, but no large-scale awning is present.

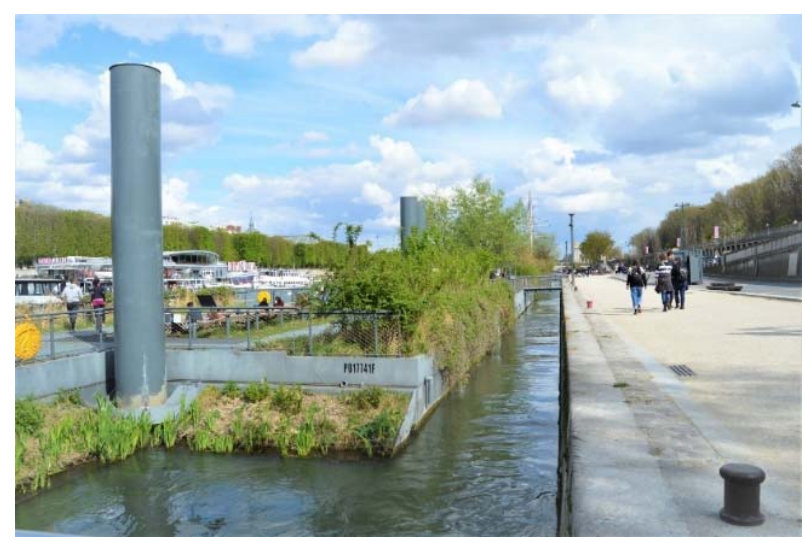

Figure 3: Vegetal riverfront barges. (Source: E. Redza.) 
The largest concern point on the site is related to the accessibility for elderly and disabled people from the street level. Most accesses are located on historic stairs that link the street level with the bank, but comfort is limited as the rise is too high. Ramps are available on certain points, but the distances in between are excessive. On the recently developed bridges, proper access to the banks is offered.

The city of Paris succeeds to promote and inform the inhabitants and visitors. Signs on site and tourist books indicate the Parc Rives de Seine. The webpage is very informative and kept the inhabitants updated during the whole process. Studies showing the overall reduction of congestion in the surroundings are available. Social media is used a way to connect with the people. For the opening of the park, several promotional and interactive installations such as photo boots were installed, resulting in a very successful inauguration day.

\subsubsection{Discussion of the scores}

The positive image and legibility of the project is recognised. The sensory experience is pleasant even if the changes to the street are minimal. The lack of directional signage is bothersome, especially being located in the cultural heart.

The site is very lively and extensively used by people of all age categories and social classes. The use of the space is diverse, but the intended programme in containers is mostly concentrated around small catering. The lack of planned cultural and entertainment offer on the promenade is filled by non-planned and occasional activities, e.g. street artists.

Staying opportunities are provided by low-tech urban furniture. The user's comfort is noteworthy, but an issue on access for disabled people was observed. No proper shelter for unfavourable weather conditions is provided.

The site is easily accessible by public transport as it is located in the centre of Paris. The fluxes of soft traffic are very high and the shared promenade is notably working. The priority does not lie on one specific user, but flows are self-regulative. Again, the access for disabled people are very restricted and need improvements.

The space feels safe due to the constant flow of people, the presence of safety officers, the mixed programme and the clean looking infrastructure.

From a sustainability point of view, the project scores excellently on low-cost, low-tech and low-maintenance as the infrastructure is reversible and adaptable. Effort to boost biodiversity are made and noise pollution is drastically reduced by suppressing car traffic.

The Parc Rives de Seine scores $79 \%$ on the comprehensive framework.

\subsubsection{Conclusion on case study}

The redevelopment of the banks of the Seine chased away car traffic to liberate space for people. The former motorway and tunnels have remained unchanged, but reversible installations providing sitting and staying opportunities were installed. The linearity of the street is appreciated for promenades, either by foot or by bike. The sidewalks offer stop zones and the former car lanes suggests a linear movement. The reconquered street forms a shared space where soft transport modes fuse with pedestrian flows.

Containers, moveable furniture and sports facilities are placed all along the promenade, establishing a public belt over seven kilometres. Floating relaxation gardens and green stops are provided on the right bank and efforts are made to reduce noise and air pollution and to boost the biodiversity in the city. The biggest shortcoming on both banks is the access for disabled people as ramps are located on inadequate intervals.

The project is a nice example of how minimal interventions in a central urban landscape can make a space lively again, ending with a score of $79 \%$. 
Table 3: Scores per criteria and sub-criteria on Seine Banks.

\begin{tabular}{|c|c|}
\hline \multicolumn{2}{|r|}{$0.280 \%$} \\
\hline GPOL1: & 5 \\
\hline GPOL1: & 4 \\
\hline GPOL1: & 5 \\
\hline \multicolumn{2}{|r|}{$0.204 \%$} \\
\hline MOBI1: & 3 \\
\hline MOBI2: & 4 \\
\hline MOBI3: & 4 \\
\hline MOBI4: & 4 \\
\hline MOBI5: & 2 \\
\hline \multicolumn{2}{|r|}{$0.126 \%$} \\
\hline LIFE1: & 4 \\
\hline LIFE2: & 5 \\
\hline LIFE3: & 5 \\
\hline LIFE4: & 3 \\
\hline LIFE5: & 4 \\
\hline \multicolumn{2}{|r|}{$0.096 \%$} \\
\hline STAY1: & 1 \\
\hline STAY2: & 5 \\
\hline STAY3: & 3 \\
\hline STAY4: & 4 \\
\hline STAY5: & 3 \\
\hline \multicolumn{2}{|r|}{$0.040 \%$} \\
\hline SAFE1: & 5 \\
\hline SAFE2: & 4 \\
\hline SAFE3: & 2 \\
\hline SAFE4: & 5 \\
\hline \multicolumn{2}{|r|}{$0.047 \%$} \\
\hline NEIGH1: & 5 \\
\hline NEIGH1: & 4 \\
\hline NEIGH1: & 5 \\
\hline \multicolumn{2}{|c|}{ TOTAL: $0.79 \%$} \\
\hline
\end{tabular}

\section{CONCLUSION}

The research aimed to develop a comprehensive framework assessing urban motorway removal in a central urban context in order to improve mobility and public life. The aim was to provide a multi-criteria analysis of urban motorways refurbishments. As a result of the findings, the methodology proposed a hierarchy based on four criteria describing the quality of an urban motorway refurbishment:

- Government policy (30\%)

- Mobility experience (30\%)

- Urban space (35\%)

- Identity of the neighbourhood (5\%).

The government policy tackles the measures the government is making and in what way, stressing the importance of calmed traffic but also awareness of the people and communication between the government and the citizens. The mobility experience emphasises the importance of safe and continuous pedestrian and bike paths, a good 
accessibility by public transport, a stimulating adventure of the townscape and the integration of access for disabled people. The urban space parameter is further divides into three strongly interlinked subcategories: attractiveness and liveliness on site $(15 \%)$ which involves the programme, aesthetics, sustainability and legibility; the user's comfort (15\%) which includes protection from climate, low noise pollution, a positive sensory experience at eye level, the design and arrangement of urban furniture and providing cleanliness, responding to fundamental human needs and practical aspects; safety (5\%) which implicates adequate lighting, overlapping programme and surveillance. The comprehensive framework allows a ranking of different projects, but can also be used to improve a project by assessing several proposals in order to achieve the best possible result.

\section{ACKNOWLEDGEMENT}

The first author would like to thank the Architectural Engineering department of the Vrije Universiteit Brussel and the Bruface programme.

\section{REFERENCES}

[1] Claris, S. \& Scopelliti, D., Cities Alive: Towards a Walking World, London, pp. 2028, 2016.

[2] Cairns, S., Goodwin, P. \& Hass-Klau, C., Traffic Impact of Highway Capacity Reductions: Assessment of the Evidence, Landor Publishing: London, 1998.

[3] Cairns, S., Atkins, S. \& Goodwin, P., Disappearing traffic? The story so far. Municipal Engineer, 151(1), pp. 13-22, 2002.

[4] Wojnarowska, A., Model for assessment of public space quality in town centers. European Spatial Research and Policy, 23(1), pp. 81-109, 2016. DOI: https:// doi.org/10.1515/esrp-2016-0005

[5] Gehl, J., Cities for People, Island Press: Washington, 2010.

[6] Aménagements des berges de Seine - Rive gauche; Plan de déplacements urbains Îlede-France, Online. http://www.pduif.fr/IMG/pdf/75-amenagement_berges_seine_rive_ gauche-vdp_vf.pdf. Accessed on: 11 Apr. 2017.

[7] Piétonnisation des Berges rive droite: pourquoi le projet est pertinent; Paris, Online. www.paris.fr/berges. Accessed on: 11 Apr. 2017. 